\title{
A FEW DREAM ANALYSES
}

BY MEYER SOLOMON, M.D.

Assistant Attending Neurologist, Maimonides Hospital, Chicago

$\mathrm{H}$

ERE are four dreams which occurred in more or less normal individuals.

Their analyses and interpretations are briefly presented. No extended explanations are entered into, nor are they necessary since the soundness, truth and accuracy of the latter cannot, it seems to me, be much doubted.

The method employed was that described in a previous article. $^{2}$ It consisted of introspection, concentration of the attention and conversation.

No conclusions are here drawn. I may merely note that many of the conclusions of the Freudian school, with respect to the function and meaning of dreams, are not only not supported but, on the other hand, are sharply contradicted.

The conclusions of the author, as numerically tabulated in two previous papers, ${ }^{3}$ and as somewhat more fully explained in another article, ${ }^{4}$ are here fully confirmed.

\section{CAse 1}

\section{DREAM AND ANALYSIS}

My sister $M$. has been troubled by recurrent axillary

1 On reading the proof of this paper the writer is reminded that he is somewhat outside the pale of normality since, from childhood, he has suffered from a disorder of speech - stuttering (a veritable psychoneurotic disorder). This information is offered because of the fact that it was the writer who had the first dream here detailed.

'In Journal of Abnormal Psychology, June-July, 1913.

${ }^{8}$ "A Contribution to the Analysis and Interpretation of Dreams Based on the Motive of Self-preservation," American Journal of Insanity, probably the forthcoming number, and "Analysis and Interpretation of Dreams Based on Various Motives," Journal of A bnormal. Psychology, June-July, 1913. Also "On the Analysis and Interpretation of Dreams Based on Various Motives and on the Theory of Psychoanalysis - Reply to Dr. Putnam," Journal of Agnormal Psychologr, 1914.

4"Interpretation of Dreams Based on Various Motives," International Clinics, December, 1913. 
abscesses for some time. For the past week she had been considerably annoyed by a single, rather large and acutely inflamed axillary abscess. I had ordered hot applications. She was neglecting proper treatment and would not let me examine it for fear that I would insist on opening it. Last night, before retiring, my mother told me the abscess surely needed attention. My sister still persisted in her decision to let nature take its course, and refused examination or treatment.

A few minutes later I went to my room, undressed, turned out the light and got in bed. While dozing off to sleep the treatment of the axillary abscess came to mind. I thought it might spread and I might have to open it. I then saw before me a red, swollen, pointing abscess bulging downward from the right arm-pit (where my sister's abscess was, in fact, located). This must now be opened, I thought. I proceeded to open it. It was necessary to make a deep incision. I saw the lips of the cut wound separate and the pus pour out from the abscess cavity. The abscess was very pointed. The wound now had two lips, an upper and a lower, both of which gradually came almost to a point and diverged from each other as they were followed from the depth of the wound to the skin surface. This at once reminded me of the sharp-pointed mouth of an animal. This momentarily imagined similarity caused an immediate transformation of the wound so that I next saw before me the representation of the lower part of the face of a fox. At this point I thought to myself: "This is strange. How is it that I see a fox's face?" My sense of criticism was aroused, and I awoke. I at once reviewed the series of associated thoughts as related above, so that $I$ would remember them in the morning. Later, I fell asleep. In the morning I recorded the experience as recited here.

Had my association and flight of ideas continued uninterrupted, there is no telling what series of associations might have resulted. The body of the fox might have made its appearance, a series of exciting occurrences centered about the fox and myself or others might have next taken place, only to again give way to another series of associated thoughts centered about one or the other of the elements 
of the dream, and so on. We can thus easily see how chance association of ideas, dependent on our education and experiences in life and our pre-sleeping thoughts, especially of happenings of the preceding day and recent past, may initiate a dream, the content of which may be related to any of our instincts.

\section{INTERPRETATION}

In the dream here given there are several factors to consider. The first thoughts were about my sister's abscess. Then came my fear that the abscess might go from bad to worse and require incision. By anticipation $I$ at once see the abscess as I feared it might become. I am already opening it. I had had just such cases in the past. The experience is connected with my professional duties. I am following the profession for three reasons: (1) egocentric and self-preservative - to make a living; (2) altruistic; (3) scientific - spirit of investigation. All of these can be shown to be, in the end, centered about the motive of selfpreservation, directly or indirectly. I was probably more concerned about the outcome of my sister's abscess than I might have been had another been so afflicted. But the series of associations might have occurred had I had that experience with any patient in my office. Moreover, had the trend of thought not been broken, there might have occurred some experience with the fox which would have been directly centered about the instinct of self-preservation. Were I a hunter I might have seen myself hunting foxes; were I a dealer in animal skins, there might have been a different line of associations, etc. Moreover, the later dream experience may be very vivid and well remembered, while the antecedent inciting thoughts may be very dim or entirely forgotten.

Freudians may suggest that the fox may be symbolic of a latent thought. After an impartial analysis of myself I can attach no intimate significance to the fox, except that the general impression which had been left on my mind from the story-books of my school-day and later period was that the fox was a crafty, ferocious animal very much to be 
feared by man. Consequently the word fox was always intimately related to thoughts of danger to myself, and hence of desire for safety (self-preservation). In the instance here recited, however, the introduction of the fox was conditioned purely by association due to imagined resemblance in shape between the incised abscess and the face of a fox.

We can see in this dream-state the significance of association of ideas, especially as determined by past experiences and by the knowledge of the dreamer with regard to the possible outcome of the condition.

The fear that my sister's axillary abscess might progress from bad to worse was the beginning of the flow of ideas. Thus a fear, dependent on a wish (for the abscess to disappear) with relation to my sister (fraternal instinct, originating from altruism and, indirectly, mainly from selfpreservation), was the means of initiating the dream thoughts.

It is plainly seen in this dream how chance internal and external associations, dependent on past experiences, education and presleeping thoughts, especially of the events of the preceding day, may incite a dream which later, by association, may be intimately related to any one or more of our instincts. These dream thoughts do not necessarily point to any special hidden, "unconscious" complexes of the dreamer, but rather indicate the general wishes, fears and mental trends more or less common to all mankind, although, of course, this is greatly conditioned by external and somatic stimuli, and by the complexes and special reactions of the individual.

The dreamer may bring into relation with his chance associations some of the wishes, fears, expectations, etc., which have been of particular concern to him within the recent past, especially his experiences and thoughts of the presleeping state and of the day before. Naturally we find that the content and direction of the mental processes in dreams is greatly conditioned by the recency, frequency, duration and intensity of past experiential life, the meaning to the dreamer, and the relation to his personality and constellations. 
Case II

DREAM AND ANALYSIS

The following dream which Mrs. C. had last night was related to me at 1 P.M. to-day. As a prefatorial remark I may say that Mrs. C. is a married lady, sixty years of age, of Hebrew faith. Last night was the first night of the beginning of the Feast of the Passover, a holiday celebrated by the Jews in commemoration of the freedom of the Jews from the bondage of Pharaoh and their exit from Egypt under the leadership of Moses. Mrs. C.'s son N. had that evening brought home a bottle of cognac. Mrs. C., who does not recall when she last tasted cognac, had partaken too freely of it last evening. Still worse, she had taken it on an empty stomach, just before her meal, and when, in fact, she was quite hungry. The cognac destroyed her appetite, upset her, made her at first happy, foolish, witty and restless, only to be soon followed by its depressing effect, so that Mrs. C. fell soundly asleep immediately after supper. She awoke a little after midnight. Another son, M., came home at this time. After a brief conversation, Mrs. C., who had by this time entirely recovered her normal state, returned to sleep. Her bedroom adjoined the kitchen. While she was gently dozing off to sleep she heard the constant pit-pat, pit-pat of drops of water which were dripping from the faucet into the basin of the sink. This made a disagreeable noise which annoyed her and kept her awake. This happened very frequently in the past - as a matter of fact almost every night. However, the dripping could be stopped by turning the handle of the faucet so that it had a perfect anteroposterior position. For this reason she had never taken the matter up with the landlady, who lived in the flat below. As her husband was in the kitchen, Mrs. C. called to him to turn the handle of the faucet to an exact median position so that the drip-drip of the leaking faucet would cease. This Mr. C. did, and the noise stopped. Soon thereafter, Mrs. C. says, she fell asleep, only to have the dream detailed below. She could not give the train or content of her thoughts from the moment her husband fixed the faucet and stopped the dripping to the beginning of the 
dream. But she knows the dream occurred very shortly thereafter, since, after she had awakened from the dream, she walked into the kitchen and on looking at the clock saw that it was 1 A.M., while she had gone to her bedroom about fifteen minutes or so before. Here is the dream with analytic explanations interjected in parentheses here and there:

Mrs. C. was standing in the kitchen of her flat (where the water had been dripping from the faucet in the sink). Mrs. B., the landlady of the house, opened the kitchen door which led out to the rear porch, and entered the kitchen. "I came up to have a little talk with you," said Mrs. B. "Sit down," rejoined Mrs. C. Mrs. B. sat down. The sun was out and shining brightly. It seemed to be early afternoon. (It was quite customary for Mrs. B. to come up the back stairs, from her flat below, to the kitchen of Mrs. C.'s flat, where the two women would have a morning or midday chat about cooking, home affairs, the neighborhood gossip, etc. Mrs. B. was a very exacting but selfish landlady. She did not live up to the terms of the lease which Mrs. C. had taken for her flat. There had been much complaint by Mrs. C. all winter long about the poor supply of steam and hot water; Mrs. B. refused to furnish new windowshades for the flat, etc. Mrs. C. was much incensed over this, spoke frequently of breaking the lease and was much embittered toward Mrs. B. The family W. in the flat above were moving on May 1 - next week - because they had had a disagreement with Mrs. B. Mrs. C. does not recall that she had any thought associations in the dream; which finally led to Mrs. B.'s entering the flat. For instance, she denies that there was any such association as this: The water dripping down into the sink might have suggested to her the floor of the kitchen, the room below, Mrs. B., and then her entrance into the room on a visit.) Mrs. B. looked up at the ceiling in the corner of the kitchen near the door leading to the porch. She noticed that the ceiling was wet. She immediately called Mrs. C.'s attention to this and at once entered into a torrent of abuse of and complaint about the $W$.'s in the flat above. (Was there not a relation here between the ceiling and the dripping faucet, and between the tirade 
against the W.'s and the disagreement Mrs. B. had actually had with them?)

Mrs. C. looked up in surprise at the wet ceiling. While both Mrs. B. and Mrs.C.were gazing at the corner of the ceiling, the latter gave way at the spot where it was wet. Then the plaster from the rest of the ceiling began falling to the kitchen floor. It seemed now that the rear door led not onto the porch but to a bedroom in the rear of the kitchen (just as conditions were in the B- Street flat, where Mrs. C. had lived for fifteen years, in poverty and misery). She felt that she was now in the kitchen of the $B$ - Street flat. (It may be noted that in the B- Street flat it was a common occurrence for water to overflow and run through to and even drip from the ceiling of the room below. Perhaps the wet ceiling at once recalled the $\mathrm{B}-$ Street flat.) The plaster on the rear wall (where, in fact, in the kitchen of the present flat, there was a long clothes closet, but which, in the dream, was between the kitchen and the rear bedroom) began to fall in. The framework, made of perpendicular sticks at intervals of every two or three inches (as most frameworks on buildings are constructed according to Mrs. C.'s knowledge), was exposed in great part. Portions of the framework were even broken down, so that there was an opening directly through the wall into the rear bedroom. There, also, in the bedroom, the ceiling was falling in. The plaster fell all about the kitchen, filled the corners, and, massed together against the door which led from the kitchen to the rear bedroom, prevented the door from being opened. (In the B-Street flat it was by no means an uncommon occurrence to have pieces of plaster come falling down from the ceiling every now and then, due to repeated leaking of water through the floor of one flat to the ceiling of the flat below.)

Mrs. C. and Mrs. B., frightened, with heads bent and hands above their heads to protect the latter, went screaming, madly rushing past the pantry and bathroom into the dining-room and parlor of the flat. (The flat on B - Street did not have a pantry, bathroom, dining-room or parlor. The present flat did.) Mrs. C. was now in her present flat. Mrs. B. ran, screaming, down the steps to her flat on the floor below. Mrs. C. stayed in the dining-room of her flat, frightened, but doing her 
best to control herself and not make a scene or arouse the neighbors.

L., daughter of Mrs. C., came rushing in from a side room. L. looked about surprisingly calmy and collectedly (ordinarily $L$. is very easily confused and loses control of herself in emergencies), and asked, "What has happened here?" and then said to he mother: "Come on. We can't stay here over night. Let's get our clothes, pack up and get out." Mrs. C. replied, "Certainly. But can we move with this stuff? We can't get it out, and everything is spoiled. I'm going to call up Mrs. B. and make her pay for it." "All right," said her daughter, "bring her up and I will get the clothes and do what I can." Miss L. went boldly into the kitchen in spite of the fact that the plaster was still falling down. She tried the door from the kitchen to the bedroom, but the plaster was so piled up against it on the kitchen floor that the door, which opened into the kitchen, could not be opened. "Let us get through the wall here," shouted L., and, suiting the action to her word, she rushed to the disemplastered wall, with its exposed framework partially broken down, which separated the kitchen from the rear bedroom. She worked hard and furiously in her efforts to work her way into the bedroom to get the clothes, etc. (Where, in the dream, the rear wall of the kitchen is located, there is, in reality, built against the length of this kitchen wall, a long clothes closet, which projects into the kitchen. The fusion seen in the next portion of the dream is thus easily understood.)

The scene became somewhat more complicated as L. was working to fight her way through the wall. First, she would be smashing the wooden framework of the wall; then she would be pulling clothes from the closet built against the wall (as was the real condition in the kitchen of the flat); back again to breaking through the wall, again snatching clothes from the closet; this repeated over and over again.

As Mrs. C. contemplated the scene of wreckage, this thought came to mind: "Now we must move whether we want to or not." (Remember that the family expected to move shortly.)

Mrs. C. next went down for Mrs. B. “Mrs. B.," she said, "come upstairs. I want to show you how things look. We can't stay here another night. Come up and look at how things 
are." Mrs. B., in her usual cool manner, walked up and surveyed the wreck. Mrs. C. called her attention to the conditions present, speaking forcibly and angrily: "Why, the ceilings have fallen in in both rooms. The wall is broken down. Look at the bed in the bedroom. It's all covered with plaster, absolutely spoiled. We can't use it any more. Our furniture in these rooms is spoiled. I won't stand for this. I am not responsible or liable for what happened here. It is your house. You are responsible for this. You can blame the woman in the flat upstairs, but that has nothing to do with me. You will have to make good and pay for all the damage in my home."

Mrs. B., in her usual exasperatingly calm way, replied, coolly and critically: "All right, Mrs. C., I'll pay for it all. Certainly. What do you mean, Mrs. C.? I shall have to pay for all this, you say? Did I spoil it?" Mrs. C. rejoined: "What do you mean, Mrs. B.? Did I spoil it? The house belongs to you and you're responsible. We can't stay here another minute. We'll move this very day." "You are right, Mrs. C.," said Mrs. B. "You don't want much. I don't think I must do what you say." "If the ceiling was in good condition it would not cave in. You don't look after the house properly," answered Mrs. C. (This is, in fact, exactly what Mrs. C. had often told Mrs. B. in the past.) Mrs. B. again replied that she considered herself in no way responsible and thereupon abruptly and stifly walked from the kitchen to the dining-room and down to her flat below.

At this point L. chided her mother for telling Mrs. B. she would have to pay for all the damages. Mrs. C. explained to her daughter why Mrs. B. should be held accountable. In proof of her standpoint she reminded her daughter that a few months ago one Mrs. S., who lived nearby, left home early one morning and came home later, only to find that all her furniture had been ruined by steam which had escaped from an imperfect valve, and which had, without warning, been turned on that morning for the first time that winter. In this instance the landlord was held responsible and Mrs. S. received payment for the damage to her furniture. The daughter recalled the case. (This was, in fact, true.) "How can we sleep here to-night?" Mrs. C. asked her daughter. "Certainly not," replied $L$. "We can't stay here to-night. Let us get our 
stuff and get out of here." "By no means," said Mrs. C., "we must stay in the flat to-night, at least. Let us put the beds in the parlor for to-night. We've got to leave here to-morrow."

At this point Mrs. C. awoke. The dream scenes at once came to mind. She felt that everything she had dreamt was true and yet could not realize that it was. She got out of bed and went into the kitchen to see if it really was true. All was quiet and in order. She was surprised. She glanced up at the clock. It was 1 A.m. She went back to bed. She was awake for a short time, recalling the dream. iLater she fell asleep. Next day she brought the dream to me and we co-operated in the analysis.

\section{INTERPRETATION OF THIS DREAM}

With this dream as a basis, the general principles of the analysis of dreams could be extensively elaborated. However, as I have elsewhere given what I believe to be the essentials of dream interpretation, I shall not endeavor to elaborate the ideas in this place and to give them special application to this case.

We can note in this dream the importance of association and flight of ideas. We appreciate here the rôle of reminiscences of past experiences, of things as they are and used to be. The recent experiences, wishes, fears, dislikes, etc., are well brought into active play. The kaleidoscopic picture with fusions (of ideas and scenes) is shown, with its dependence on rapid association of ideas. The law of chance or probability in the mental world, as determined by past experience and knowledge, is clearly appreciated.

Anticipation and retardation of ideas and scenes can be here found. And certain past experiences, of decided intimacy to the dreamer, but not of a sexual nature, are shown to play a prominent part.

As to the underlying motives here present, there are several. The appeal to the instinct of self-preservation is frequent, pronounced and most dominant. The love of home and family, characteristic of every wife and mother, plays a pronounced rôle.

Perhaps by saying that the dream is, in a way, an ex- 
hibition of the mental make-up of the dreamer, and is significant of her self-expression, of her personality, we strike at the very root of the situation.

Let us note especially that we see no psychical repression here, in the sense in which this term is used by the Freudian school; there is no far-fetched symbolism, no particular sexuality; no special infantile or childhood experiences are found to be at the bottom of the dream.

There is no transformation of latent into manifest content. In fact, most of the principles of the Freudian conception of dreams finds little, if any, support here. On the other hand many of them are quite definitely contradicted.

\section{Case III}

\section{DREAM}

Mr. E. S. dreamt that his wife G. told him that his five-year old daughter $E$. was having trouble in swallowing water. With "a lump in his throat," and a palpitating heart, frightened, and fearful lest his daughter had contracted hydrophobia as the result of a recent dog bite, he cried out in terror: "What is that you say?"

\section{ANALYSIS}

One week ago little Miss E., five-year old daughter of Mr. E. S., had been bitten by a dog, on the porch of their home. The dog belonged to their next-door neighbor and friend. Although the circumstances were such that it was clearly a case about which one need have no concern, since - it seemed that the dog had snapped at the little girl because of the fear that the child, who had passed by the dog while it was eating, might take away its food; nevertheless, $\mathrm{Mr}$. E. S. insisted that no chances should be taken. Accordingly the dog was sent to the dog-pound for observation for fifteen days, and the child was being given the Pasteur treatment for the prevention of rabies. Mr. E. S.'s wife, G., was a very devoted mother, closely guarded her children, and daily kept her husband (who was the family guardian 
and protector) informed of the conduct and condition of the children, of whom there were three.

\section{INTERPRETATION}

The fear of his child developing rabies was the basis of the dream. This was, of course, determined by the wish for the health and welfare of his child. This, in turn, was dependent on the paternal instinct. I shall not here analyze the origin of the paternal instinct, but it is the instinct of self-preservation which is, indirectly, most fundamental.

There is no indication of the rôle of psychical repression of "unconscious" thoughts, of transformation of latent into manifest content, of symbolism, of sexuality, of infantile and childhood experiences.

\section{CAse IV}

\section{DREAM}

Mrs. G. dreamt that her daughter S. had left home to look for a position. When she returned home she entered the flat looking very much depressed. She walked into the kitchen, sat down, and on her mother's asking her whether she had obtained the position, she immediately burst out crying. She sobbed out that she had gone to the address given her by the employment agency which was endeavoring to secure a position for her, but that another girl had applied there before her and was successful in securing the position. She had then returned to the office of the employment agency, she sobbingly related, and there she was informed by the manager that in some way or other the other girl must have received information concerning the position in question, that he had not given this information to her nor had he sent the girl to the place, and that he could only say that "some people certainly were mean."

\section{ANALYSIS}

Miss S. had left home about 10 A.M. that morning to seek a position with a firm to which she was being sent by an 
employment agency. She had arisen rather later than usual that morning, and had left the house somewhat later than she should have done. Her mother bade Miss S. good-bye and wished her luck in her quest. After the daughter had departed, Mrs. G. leaned back in her rocker and, among other thoughts, the thought arose in her mind that her daughter might reach the place too late; that perhaps some other girl might have known about the vacancy and might have applied for the position at an earlier hour that morning. Soon Mrs. G. gradually dozed off and fell asleep. And then she had the dream above related. The fear of what she imagined, in her waking state, might take place, is reproduced as an actuality in her dream.

As an explanation of her daughter's bitter weeping, because of the loss of the position, Mrs. G. recalled that on a previous occasion, some four months ago (since which time Miss $S$. had remained at home helping with the housework), Miss S. had been discharged from her position for coming late quite regularly every morning. On her return home that evening she came into the kitchen, sat down for awhile, and then suddenly burst out crying, complaining about the loss of her position; declared that fortune was against her, that she was born under an unlucky star, that nothing ever came her way, "etc. Moreover, every now and then, when she has suffered keen disappointments and things are looking blue to her, the poor girl finds an outlet in "having a.good cry and letting it out of her system" as the mother puts it.

Notice how in this dream the dreamer has made an effort at explaining how it was possible for another girl to have arrived at the position at an earlier hour than her daughter. So far as she knew, in her waking state, her daughter was the only one who was sent to apply for the place of employment in question. Having enacted, as an actual occurrence, her waking fear, she next permits her daughter to elaborate an explanation for this occurrence. She has her daughter tell of a return to the employment agency with the lame explanation offered, in the dream, at the latter place. As a matter of fact no explanation is given in the dream; it is but an attempt at such. 


\section{INTERPRETATION}

The fear of her daughter not obtaining the position arises from the wish that her daughter would secure employment. (It may be noted that later in the day Miss S. returned with the joyful news that she had been successful in obtaining employment with the concern to which she had been sent.)

The underlying motives may be thus briefly enumerated: The maternal instinct is predominant. Moreover, Miss S. had been out of work for some months, and was now sorely in need of new clothes. Again, the income for the household was rather meager, and if her daughter worked, although she might not contribute anything toward the support of the home, at least she would not have to be supplied with ready cash, etc. Thus we have the instinct of sympathy and altruism, aside from the maternal instinct. The regard for the welfare of the home is explained by the familial instinct, which has a complex origin which need not here be gone into.

It is noteworthy that we have an absence of sexuality, of psychical repression, etc., as elaborated by the Freudian school.

I am well aware that my remarks in the above analyses and interpretations are very brief and superficial. An elaborate analysis of any one of these dreams would lead us far afield. This, I feel, is unnecessary in the presentation of the dreams here reported. 